\title{
Pitted keratolysis: an infective cause of foot odour
}

\author{
Pablo Fernández-Crehuet MD PhD, Ricardo Ruiz-Villaverde MD PhD
}

$\mathrm{A}$ 23-year-old man was referred with a one-year history of malodorous exudative lesions on the soles of both feet. His condition seemed temporally related to the use of occlusive footwear at work and was associated with a burning sensation. On physical examination, multifocal, cerebriform maceration and crateriform pitting with superficial erosions were seen on both soles. The pitting became more prominent when the patient's feet were water soaked. Examination with a Wood light showed no fluorescence. These skin findings are characteristic of pitted keratolysis. We prescribed clindamycin 1\% topical solution twice a day and solution of aluminum chlorohydrate $25 \%$ alcoholic solution as antiperspirant. Two weeks later, the patient's condition had improved substantively.

Pitted keratolysis is common among athletes and individuals in professions with greater use of occlusive footwear. ${ }^{1}$ Patients may experience hyperhidrosis, foot odour and sometimes itching or burning while walking, although most cases are asymptomatic. The lesions tend to be multiple, superficial rounded depressions, 0.5 to $7 \mathrm{~mm}$ in diameter, affecting mainly weight-bearing areas of the soles. Palms are less commonly involved. The condition is caused by an infection of the stratum corneum by Kytococcus sedentarius (formerly Micrococcus spp.), though Dermatophilus congolensis and Corynebacterium spp. have also been implicated. ${ }^{2}$ Bacteria proliferate and produce proteinases that destroy the stratum corneum, producing the characteristic craters or pits. The odour linked to pitted keratolysis is due to the production of sulphur compounds.

The main differential diagnosis includes tinea pedis, verrucae, punctate palmoplantar keratoderma and palmoplantar hypokeratoses. ${ }^{3}$

The diagnosis is clinical. ${ }^{2,3}$ Cultures, if taken, show gram-positive coccobacilli or bacilli. Examination with a Wood light is not reliable for diagnosis and may be negative or show coral-red fluorescence when Corynebacterium spp. is implicated. ${ }^{2}$ Dermoscopy usually reveals abundant pits with well-marked walls that sometimes

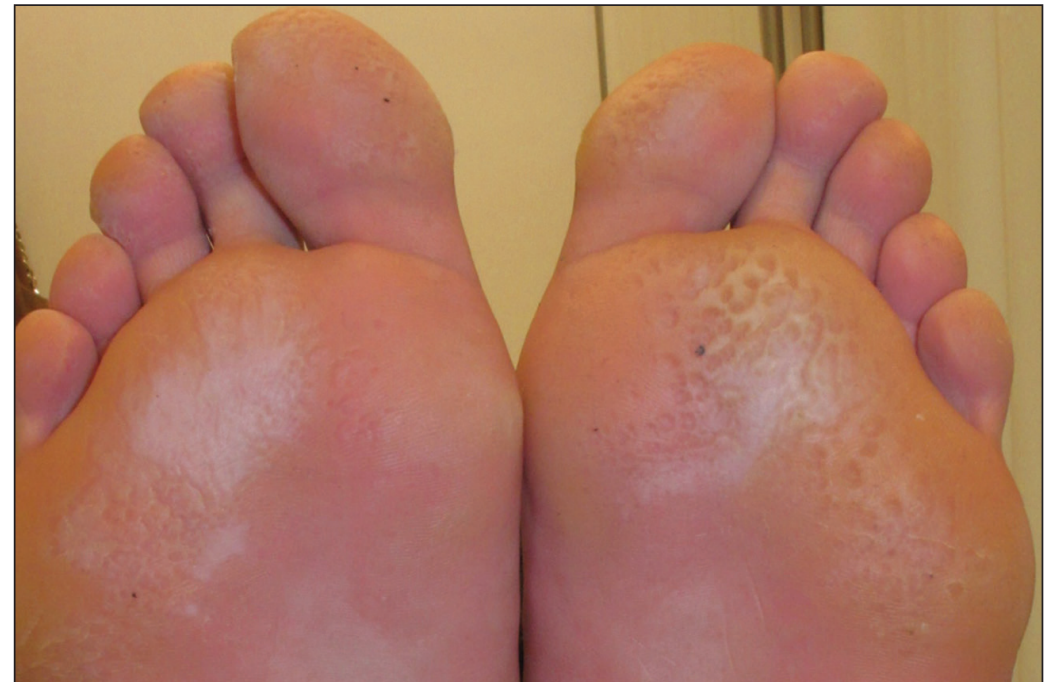

Figure 1: Multifocal, cerebriform maceration and crateriform pitting with superficial erosions in both soles of a 23 -year-old man with a one-year history of foot discomfort and odour associated with the use of occlusive footwear.

show the bacterial colonies. ${ }^{4}$ A potassium hydroxide examination of the lesions can exclude tinea pedis. ${ }^{3}$

Changing footwear and socks regularly as well as airing out or rotating shoes is key to management. Topical antibiotics are the first line of medical treatment. ${ }^{1,3}$ Erythromycin 1\% (solution or gel), clindamycin, fusidic acid or mupirocin $2 \%$ are recommended. ${ }^{1,3}$ Botulinum toxin or iontophoresis for localized treatment of sweating may be useful. ${ }^{1}$ There is also evidence for adding benzoyl peroxide to the antibiotics treatment. ${ }^{5}$ Prognosis is excellent, and lesions usually resolve in three to four weeks.

\section{References}

1. van der Snoek EM, Ekkelenkamp MB, Suykerbuyk JC. Pitted keratolysis: physicians' treatment and their perceptions in Dutch army personnel. J Eur Acad Dermatol Venereol 2013;27:1120-6.

2. Blaise G, Nikkels AF, Hermanns-Lê T, et al. Corynebacteriumassociated skin infections. Int J Dermatol 2008;47:884-90.

3. Pranteda G, Carlesimo M, Pranteda G, et al. Pitted keratolysis, erythromycin, and hyperhidrosis. Dermatol Ther 2014;27:101-4.

4. Lockwood LL, Gehrke S, Navarini AA. Dermoscopy of pitted keratolysis. Case Rep Dermatol 2010;2:146-8.

5. Vlahovic TC, Dunn SP, Kemp K. The use of a clindamycin $1 \%$-benzoyl peroxide 5\% topical gel in the treatment of pitted keratolysis: a novel therapy. Adv Skin Wound Care 2009;22: 564-6.
Competing interests: None declared.

This article has been peer reviewed.

The authors have obtained patient consent.

Affiliations: Dermatology

Department (FernándezCrehuet), Hospital Alto

Guadalquivir, Andújar,

Spain; Dermatology

Department (Ruiz-

Villaverde), Hospital

Universitario Virgen de las

Nieves, Granada, Spain

Correspondence to:

Pablo Fernández-Crehuet, pablocrehuet@hotmail.com

CMAJ 2015. DOI:10.1503 /cmaj.140809 